\title{
Prefiro a escola: percepções de alunos e familiares sobre o ensino remoto emergencial
}

Robson Lima de Arruda ${ }^{1}$

\section{RESUMO}

O texto expressa a avaliação dos alunos e familiares de uma turma de $5^{\circ}$ ano do Ensino Fundamental sobre o Ensino Remoto Emergencial (ERE) realizado em 2020. Os dados foram gerados numa reunião remota entre família e escola, em que foram apresentadas as percepções dos participantes acerca do ano "pandêmico", das aulas remotas, bem como da aprendizagem. Os resultados ressaltaram a importância da escola como instância de socialização e de aprendizagens múltiplas, evidenciaram a necessidade de ampliar a relação entre família e escola durante e após a pandemia.

Palavras-chave: Escola e família. Ensino Remoto Emergencial. COVID-19. Educação. Sociabilidade. 


\section{I prefer the school: perceptions of students and families about remote teaching}

\section{ABSTRACT}

The text expresses the assessment of students and family members of a 5th grade class of Elementary School on Emergency Remote Teaching (ERE), carried out in 2020. The data were generated in a remote meeting between family and school, in which the perceptions of the students were presented about the "pandemic" year, the remote classes, as well about as learning. The results highlighted the importance of the school as an instance of socialization and multiples learnings and highlighted the need to expand the relationship between family and school during and after the pandemic.

Keywords: School and Family. Emergency Remote teaching. COVID-19. Education. Sociability. 


\section{INTRODUÇÃO}

O ano de 2020 inaugurou um capítulo na história recente da humanidade demarcando inúmeros desdobramentos decorrentes das alterações substanciais no curso das relações humanas. O primeiro caso de COVID-19 apareceu praticamente no romper de um novo ciclo entre um ano que se foi e outro que se iniciava, em 31 de dezembro de 2019. Num contexto de globalização como o que vivemos, com intenso fluxo migratório, não custou muito até que a doença se espalhasse mundo a fora, iniciando uma pandemia que punha em risco a saúde de pessoas, requisitando medidas de distanciamento físico para conter os seus avanços.

Segundo a Organização Pan-Americana de Saúde (OPAS) vinculada à Organização Mundial da Saúde (OMS), até 29 de janeiro de 2021, o número de mortes pelo mundo alcançava a triste marca de 2.182.867 mortes. No Brasil, até a data mencionada, o número de infectados passava dos nove milhões e as mortes haviam chegado a 222.666 (WHO, 2021)i.

Considerando as medidas de distanciamento físico, a partir do fechamento temporário das escolas e da adoção do Ensino Remoto Emergencial (ERE) como alternativa de continuidade dos processos educativos, este trabalho apresenta uma discussão sobre a perspectiva de alunos e familiares de uma turma de $5^{\circ}$ ano do Ensino Fundamental sobre tal alternativa de ensino realizado durante o ano de 2020 . Os dados foram colhidos durante uma reunião on-line, feita individualmente por chamada de vídeo, que tinha por objetivo realizar uma autoavaliação e discutir resultados do trabalho desenvolvido entre professor, alunos e familiares.

Com base nos resultados apresentados, serão abordados aspectos relevantes sobre o papel da escola enquanto instância de socialização e produção de conhecimentos. Para isso, articulam-se alguns pressupostos teóricos e conceituais de Saviani (2011), Ferreira (2020), Ramos e Ramos (2010) e Morin (2002; 2014). A despeito do uso das Tecnologias da Informação e Comunicação e do ERE, apoiamo-nos em Castells (2005), Mercado (1999), Escola, Gomes e Lopes, (2019), Nascimento e Lima (2018), Soares (2020), entre outros.

As perspectivas discutidas neste trabalho são lançadas na tentativa de contribuir com as discussões acerca do Ensino Remoto no contexto pandêmico e evidenciar o debate sobre o papel social da escola e a relação entre essa instituição e as famílias.

\section{LUGAR DE CRIANÇA É NA ESCOLA}

Pátio lotado. Barulho por todo lado. Pais, mães e responsáveis na secretaria da escola assinando a renovação da matrícula: "é você o professor do meu filho?". Toca o sinal para formar a fila no pátio: "Atenção para a chamada! Vamos formando as filas de acordo com os nomes que eu disser", fala em tom megafônico a gestora escolar. Professores em frente de cada turma. Mais falas de ordem: " $5^{\circ}$ ano $B$, sigam o professor até a sala!".

Por um momento, timidez misturada com euforia. Correria para marcar o melhor lugar na sala. "Pronto? Bom dia. Eu serei o professor de vocês. Meu nome é...". Depois da apresentação de cada aluno em uma conversa inicial, toca o sinal para o intervalo. Barulho, gritaria, agitação, vida! A rotina de uma escola lotada de crianças sabe-se como é. 
O ano letivo de 2020 começou assim em todas as escolas de Ensino Fundamental do país, quiçá do mundo. Esse movimento anual de reencontro com a escola foi interrompido devido à pandemia de um vírus que mudou drasticamente a rotina de todos os moradores do planeta. Em menos de 30 dias letivos presenciais, todos estavam em casa, aflitos, curiosos e inseguros diante da ameaça do novo Coronavírus. Houve quem pensasse na retomada das aulas em poucos dias após deixar-se as escolas e aderir ao distanciamento físico. Todavia, a situação em 2021 ainda é a mesma, em meio a uma pandemia, o mundo esperançoso com o início da vacinação, mas cauteloso perante uma segunda onda que continua ameaçando a saúde, ceifando vidas e limitando a sociabilidade nos espaços diversos.

Saviani (2011) argumenta que a escola é um importante espaço de socialização do saber sistematizado. Para ele, "a escola diz respeito ao conhecimento elaborado e não ao conhecimento espontâneo; ao saber sistematizado e não ao saber fragmentado; à cultura erudita e não à cultura popular". Além de constituir um espaço marcado pelas experiências pragmáticas e coletivas de aprendizagem, as escolas são primordiais para promover a sociabilidade e toda complexidade dela resultante: aprendizados coletivos, reafirmação identitária, ajustamento cultural, convivência solidária, formação ética e moral etc.

Na concepção de Ramos e Ramos (2010):

a socialização é um processo interativo e necessário para o desenvolvimento sociopsicológico através do qual a criança satisfaz suas necessidades e assimila a cultura, ao mesmo tempo em que, reciprocamente, a sociedade perpetua-se e desenvolve-se (RAMOS; RAMOS, 2010, p. 34).

Nessa perspectiva, entende-se a Educação como uma experiência social em que os estudantes aprendem a descobrir a si mesmo e a relacionar-se com os outros. Todavia, "essa experiência - de socialização - deve se iniciar antes da idade da escolaridade obrigatória, assumindo formas diferentes, conforme a situação, e nela devem estar implicadas as famílias e as comunidades de base" (DELORS, 1998, p. 22).

Com a pandemia, a escola esvaziou-se, temporariamente, de toda dinâmica interacional que vivifica os ambientes a ela pertencentes. Nesse contexto, os lares e as famílias foram requisitados, mais do que antes, como extensão da escola e dos professores. Tratar a casa e os familiares como uma extensão traz amenidade ao discurso de que muitos se valem para dizer que a escola foi transportada para os lares e que, "agora", os novos professores são os pais e responsáveis.

É sabido que a família é a primeira instância educadora da criança e que, portanto, a casa e o contexto social são também espaços educativos; porém, cabe reservar à escola e aos professores o seu papel, assim como cabe, do mesmo modo, para a família e o lar a assunção do que lhes compete enquanto instância social e socializadora da criança. Segundo Delors (1998):

A família constitui o primeiro lugar de toda e qualquer educação e assegura, por isso, a ligação entre o afetivo e o cognitivo, assim como a transmissão dos valores e das normas. [...] Um diálogo verdadeiro entre pais e professores é, pois, indispensável, porque o desenvolvimento harmonioso das crianças implica uma complementaridade entre educação escolar e educação familiar. Diga-se, a propósito, que as experiências de educação pré-escolar dirigidas a 
populações desfavorecidas mostraram que a sua eficácia deveu-se muito ao fato das famílias terem passado a conhecer melhor e a respeitar mais o sistema escolar (DELORS, 1998, p. 111).

Para Nóvoa (FERREIRA, 2020), a escola, sobretudo a escola pública, ocupa lugar decisivo no presente e para o futuro. Nesse sentido, advoga-se a favor de uma escola com dimensões do comum, do presencial, como espaço legítimo dos professores e alunos. Dessa forma, no atual contexto de pandemia, o autor defende que a escola não pode se fazer ausente, em especial para os mais pobres e vulneráveis:

Os outros [alunos] provavelmente terão em casa os livros, têm em casa os pais, têm em casa um conjunto de outras possibilidades de manter os seus percursos de aprendizagens. É para os mais pobres e para os mais vulneráveis que nós temos que deixar a nossa preocupação e a nossa atenção. Ah, mas os mais pobres não tem acesso à internet. Vamos à televisão. Ah, mas alguns também não têm acesso à televisão. Vamos para outro meio qualquer. Vamos inventar maneiras, mas, sobretudo não arranjemos desculpas para estarmos ausentes neste momento tão duro e tão dramático de nossas vidas (FERREIRA, 2020).

As alternativas de ERE promovidas durante a pandemia da COVID-19 são estratégias temporárias e excepcionais que demandaram de professores, alunos e família um novo modus operandi de relações. Nesse cenário, foi necessário ressignificar e reformular concepções e práticas de ensino e de aprendizagem, empreendendo esforços coletivos, a partir do uso das tecnologias e outros suportes acessíveis e adequados às necessidades e possibilidades dos estudantes.

\section{A ESCOLA NÃO É (APENAS) UM ESPAÇO FÍSICO}

A emergência da contenção da contaminação pelo novo Coronavírus requisitou que o distanciamento físico fosse adotado como principal estratégia de prevenção e propagação da doença. As escolas estão entre os principais locais que, potencialmente, poderiam colaborar para espalhar o vírus e agravar a situação da pandemia. Orientados a ficar em casa, alunos e professores precisaram recorrer ao Ensino Remoto, operacionalizado pelas Tecnologias da Informação e Comunicação (TIC), como alternativa mais viável para dar continuidade aos processos de ensino e aprendizagem. Diferente de outras pandemias do passado, a da COVID-19 ocorre num contexto em que as TIC e a internet estão disseminadas de forma ampla, desde as camadas sociais privilegiadas até as mais vulneráveis economicamente.

O mundo está em uma era digital ou, como expressa Castells, numa sociedade cuja estrutura é baseada em:

redes operadas por tecnologias de comunicação e informação fundamentadas na microeletrônica e em redes digitais de computadores que geram, processam e distribuem informação a partir de conhecimento acumulado nos nós dessas redes $(2005$, p. 20). 
Além dessas informações compartilhadas em velocidades e volumes nunca antes vistos na história humana, as redes são marcadas pela interação e sociabilidade que aproxima sujeitos, distantes geograficamente, por meio dos ciberespaços. Essa nova dinâmica desafia a escola e os professores a utilizar as tecnologias da comunicação e da informação formando uma teia comunicacional educativa.

No ciberespaço:

O espaço virtual é formado por cada computador e por cada usuário conectado nessa imensa rede que envolve todo o planeta. Não há como escapar. 0 ciberespaço tomou conta do planeta. Tragou todos - pessoas, máquinas e replicantes -, incorporando nossas virtudes e nossos defeitos. O ciberespaço deu vida à "aldeia global". Ele é o sopro vital que anima o novo mundo em formação (ESCOLA; GOMES; LOPES, 2019, p. 35).

Apesar de parecer óbvia a afirmação de que vivemos em uma sociedade em rede (CASTELLS, 2005), é preciso ressaltar que uma parte considerável da população não possui acesso às tecnologias. Nesse sentido, seria preciso um estudo aprofundado da situação socioeconômica dos grupos mais vulneráveis para observar a desigualdade social do país e sua relação com a exclusão digital na atualidade. A exclusão é uma das faces mais cruéis da desigualdade social; tem início nas diferenças e disparidades econômicas, mas se estende a outras esferas, como a educacional, cultural, digital etc.

No que tange à exclusão digital, cumpre ressaltar que ela não se resolve com a compra de um aparelho celular conectado com a internet. Incluir digitalmente é um conceito complexo e amplo. Para Rebêlo (2005), significa "melhorar as condições de vida de uma determinada região ou comunidade com a ajuda da tecnologia [...] não é alfabetizar a pessoa em informática, mas também melhorar os quadros sociais a partir do manuseio dos computadores". Nessa perspectiva:

[...] difundir a internet ou colocar mais computadores nas escolas, por si só, não constituem necessariamente grandes mudanças sociais. Isso depende de onde, por quem e para quê são usadas as tecnologias de comunicação e informação. O que nós sabemos é que esse paradigma tecnológico tem capacidades de performance superiores em relação aos anteriores sistemas tecnológicos (CASTELLS, 2005, p. 18, grifo do autor).

Do mesmo modo que possuir um celular ou computador com acesso à internet não garante inclusão digital, cumpre destacar que esse mesmo aparato não garante a aprendizagem sistemática, pois são necessárias competências e habilidades complexas sobre aprender na era digital, construindo uma rede interacional que envolva apropriação, produção e troca de conhecimentos por intermédio das TIC.

Nesse entendimento, a despeito da ideia de informação e de conhecimento, cabe evocar Morin $(2002 ; 2014)$ ao argumentar que é necessário compreender que o excesso de informações são parcelas dispersas do saber e que, no mundo moderno "estamos afogados em informações". Logo, "a informação não é um conceito de chegada, é um conceito de partida" (MORIN, 2014, p. 
27); entretanto, a produção de conhecimento é o resultado da contextualização das informações para que tenham sentido (MORIN, 2002; 2014).

Ainda que se tenha avançado na modernização de escolas com a implantação de programas, projetos e aquisição de recursos tecnológicos, é preciso reconhecer a insuficiência desse aparato, sobretudo nas escolas do campo. As pesquisas do Centro Regional de Estudos para o Desenvolvimento da Sociedade da Informação (CETIC.BR) revelam essa disparidade. Segundo um estudo intitulado TIC Domicílios 2018 divulgado em 2019, um total de 58\% dos domicílios brasileiros não têm acesso a computadores, e 33\% não tinham acesso à internet. No campo, entre as classes $\mathrm{D} / \mathrm{E}$, um percentual de $60 \%$ não possui acesso à internet. A título de comparação, entre as classes A e B, a falta de acesso é de apenas $1 \%$ e $6 \%$, respectivamente. Ainda, segundo o estudo, o celular é o mais utilizado para acessar internet: $97 \%$ dos brasileiros utilizam o aparelho para tal. No campo, o celular também é usado por $97 \%$ das pessoas, porém o estudo revelou que esses indivíduos não possuem outros dispositivos de acesso à internet. (CETIC.BR, 2019)

Para Nascimento e Lima (2018, p. 12), a expansão da internet é responsável por inaugurar novas formas de comunicação e organização social. Nesse entendimento, "os ambientes on-line de comunicação se configuram como novos ambientes de sociabilidade, de organização, de informação e de conhecimento, condições que, no nosso entendimento, podem favorecer a educação", revelam os autores.

Conforme Santos (2015), os ambientes de aprendizagem funcionam como impulsionadores e facilitadores do processo de aquisição de conhecimentos. Por isso, "cada espaço deve permitir ao aluno utilizar diferentes ferramentas para que busque seu melhor caminho rumo ao completo aprendizado" (SANTOS, 2015, p. 152, grifos nossos). Com isso, sobretudo neste contexto de excepcionalidade pandêmico:

\footnotetext{
Não podemos mais imaginar a escola como o único "espaço do saber", o professor como a única fonte de informação confiável e a biblioteca como o arquivo de dados sobre o mundo. No lugar da escola, abriu-se o mundo; o docente se tornou mais uma fonte de informação, entre as tantas que a internet nos possibilita (incluindo vídeos-aula de outros professores); e a biblioteca perdeu espaço para fontes de informação on-line, como a Wikipedia ou o Google Books, por exemplo. $O$ aluno, sem perceber, não vai mais à escola para adquirir conhecimento, afinal ele pode fazer isso em casa, no seu computador, tablet ou celular (SANTOS, 2015, p. 155).
}

Cumpre destacar que as discussões sobre tecnologia e educação não são prerrogativas desses tempos de pandemia. Há tempos, as tecnologias vêm sendo inseridas na educação e gerando novos modos de produzir o trabalho docente, como o Ensino Híbrido que, segundo Moran (2015), corresponde à combinação de diversos espaços, tempos, atividades e metodologias; entretanto:

Esse processo, agora, com a mobilidade e a conectividade, é muito mais perceptível, amplo e profundo: é um ecossistema mais aberto e criativo. Podemos ensinar e aprender de inúmeras formas, em todos os momentos, em múltiplos espaços. Híbrido é um conceito rico, apropriado e complicado. Tudo 
pode ser misturado, combinado, e podemos, com os mesmos ingredientes, preparar diversos "pratos", com sabores muito diferentes (MORAN, 2015, p. 41).

Num cenário de volta à "normalidade”, após o início da vacinação ou no pós-pandemia, o Ensino Híbrido poderá ser utilizado, considerando a possibilidade de repensar e renovar as práticas pedagógicas e educativas. Todavia, o Ensino Remoto adotado durante a pandemia, em atividades síncronas ou assíncronas, foi a alternativa mais utilizada para garantir a "presença" nesses tempos dramáticos vivenciados (FERREIRA, 2020).

Segundo Soares (2020), as aulas remotas foram implementadas de modo aligeirado, esbarrando na falta de acesso à internet de grande parte da população, em especial dos mais carentes e vulneráveis. Além disso, parte do professorado não sabia como utilizar pedagogicamente essas ferramentas. Com isso, em muitas situações, as aulas remotas se constituíram "em um mero aprofundamento das metodologias tradicionais - exercícios, correções, aulas expositivas - e não em um aproveitamento da tecnologia para desenvolver técnicas mais atrativas de aprendizagem" (SOARES, 2020, p. 8).

Isso reflete o fato de que é preciso integrar as TIC aos ambientes de aprendizagem escolar, e que os custos e a falta de domínio desses instrumentos não podem servir como argumento de resistência quanto ao seu uso (MERCADO, 1999). Nesses termos, as dificuldades com as aulas remotas são, também, consequências da falta de formação e da ausência desses recursos no cotidiano das aulas presenciais.

É importante que os professores e demais profissionais da educação escolar entendam que as tecnologias vieram para ficar e que, portanto, é necessário ressignificar os processos de aprendizagem, passando de um ensino transmissor e instrucional para "um modelo pedagógico baseado na prática colaborativa de procura do conhecimento” (GUEDES, 2018, p. 52).

Sendo assim, é pertinente ouvir e considerar o que dizem os alunos e familiares a respeito da dinâmica do ERE, afinal, essa modalidade emergencial depende de uma parceria firmada entre ambos, e a falta dessa cooperação traz implicações negativas no processo de continuidade da aprendizagem dos estudantes.

\section{4}

\section{COM A PALAVRA: OS ALUNOS E FAMILIARES}

O próximo passo deste texto consiste em apresentar os resultados de uma avaliação oral realizada com 14 alunos e seus familiares, na ocasião de uma reunião entre família e professor, por meio de chamada de vídeo pelo aplicativo WhatsApp. As avaliações foram realizadas nos dias 17, 18, 21 e 22 de dezembro de 2020 e compreendem o encerramento do ano letivo remoto de uma turma do $5^{\circ}$ ano da Escola José Batista de Souza no município de Vertente do Lério no Estado de Pernambuco. As chamadas de vídeo foram individuais, contando com a participação do professor, do aluno ou aluna e de seus familiares. Em três casos, não houve a participação dos pais, mães ou responsáveis, porém, as chamadas foram feitas. Todas elas tinham o objetivo de realizar uma autoavaliação em relação ao desempenho dos estudantes nas atividades remotas e promover interação e avaliação entre família e escola no contexto da pandemia. 
A abordagem do professor ocorreu de forma espontânea, seguindo um roteiro que incluía as seguintes perguntas: como você avalia o ano letivo de 2020 ? O que achou e como se sente em relação às aulas remotas? Como se sente em relação à aprendizagem? Acha que aprendeu?

Todas as perguntas foram feitas aos alunos e alunas, com a presença dos pais, mães ou responsáveis durante a interação. Após os alunos responderem, os familiares foram convidados a avaliar, de modo geral, as aulas remotas e a aprendizagem do aluno ou aluna ao final do ano letivo.

As respostas foram digitadas pelo professor em uma planilha durante o contato virtual e, para fins de análise, foi feita a categorização que utiliza "rubricas ou classes, as quais reúnem um grupo de elementos - unidades de registro, no caso da análise de conteúdo - o sob um título genérico" (BARDIN, 1977, p. 117). Desse modo, foram utilizados os recortes discursivos categorizados em unidades de registro e analisados em unidades de contexto.

Após análise das unidades de registro (BARDIN, 1977), categorizou-se os dados entre afirmações positivas e afirmações negativas em relação ao Ensino Remoto vivenciado pelos alunos em 2020. Cumpre ressaltar que os alunos e familiares foram estimulados a expressar sua opinião com o máximo de sinceridade, já que tal instrumento avaliativo não representaria nenhum tipo de prejuízo ou bônus aos estudantes.

\subsection{O que disseram os alunos e alunas sobre o Ensino Remoto Emergencial}

Em relação ao primeiro questionamento - como você avalia o ano letivo de 2020 ? -, os alunos foram estimulados a pensar sobre o contexto de 2020, não só nos aspectos das vivências escolares, mas de modo geral.

Nesse item, oito alunos disseram que o ano foi "bom", porém citaram a pandemia como um ponto negativo que os impediu de "sair de casa para brincar e ir à escola". Para quatro alunos, o ano foi "ruim" e o fato que justifica essa resposta foi, por unanimidade, a vontade de estar na escola. Dois alunos disseram que o ano foi bom, porque brincaram e ficaram em casa, no entanto mencionaram que teria sido melhor se estivessem na escola.

Percebe-se, com isso, que praticamente todos os estudantes questionados citaram a falta que sentiram de ir à escola e de estar nesse ambiente. Tal fato comprova o papel preponderante da instituição como socializadora e como espaço de vivências e aprendizagens (RAMOS; RAMOS, 2010; FERREIRA, 2020; SAVIANI, 2011).

No tocante ao segundo questionamento - o que achou e como se sente em relação às aulas remotas? -, os estudantes foram incentivados a avaliar as aulas remotas que tiveram, considerando as facilidades, dificuldades, limitações, tipos de atividades e de interação, entre outros aspectos.

Sobre esse tópico, nove alunos afirmaram que as aulas foram "boas" ou "mais ou menos", adjetivando-as também por "legais" e "divertidas"; no entanto, houve unanimidade quanto a preferir o ensino presencial (a escola). As justificativas foram diversas: "Estou com saudades dos amigos e dos colegas"; "Saudades de brincar e de fazer tarefas"; porque "Tava vendo pessoalmente a tarefa, os professores e os amigos"; e "A gente pode conversar pessoalmente". Outros cinco estudantes responderam que não gostaram das aulas remotas e justificaram com as seguintes afirmações: "Achei muito difícil, porque eu não tinha conexão com a internet e tive 
dificuldade de entender"; "O mais difícil era a falta de internet"; "Não dá para explicar como se fosse na escola"; "Eu tava me empolgando com os estudos na escola, em casa é ruim".

Entre os alunos que afirmaram não ter gostado do Ensino Remoto e os que disseram ter achado "bom", mais uma vez nota-se a preferência pelo Ensino Presencial na escola. Tal fato foi mencionado por quase todos os estudantes. Em suas falas percebe-se que o contato presencial é o motivo principal, seja nas atividades de ensino, seja na convivência com professores e colegas.

Para finalizar, os alunos e alunas responderam como se sentiam em relação à aprendizagem. Nesse aspecto, foram orientados a fazer uma autoavaliação sobre conhecimentos relacionados aos conteúdos das disciplinas e dos temas transversais trabalhados durante as aulas remotas. Em resposta a essa questão, sete alunos afirmaram que "sim", conseguiram aprender ou evoluir em aspectos da leitura, escrita, oralidade, matemática etc. Todavia, foram enfáticos ao admitir que avançaram em alguns sentidos, mas apresentaram dificuldades em outros.

Considerando o número de alunos que usou a expressão "um pouquinho" ou "mais ou menos" para falar se aprenderam, catalogou-se esse grupo em uma segunda categoria. Cinco crianças se encaixaram em tal grupo e justificaram que "não - aprenderam - tanto como na escola", e, ao falar que aprenderam sobre algo, sempre mencionavam outro aspecto sobre o qual não conseguiram se desenvolver a contento. Mesmo definindo que "sim" ou "mais ou menos", foi comum entre esses doze alunos a afirmação de que o Ensino Remoto ajudou, mas deixou lacunas que poderiam ter sido sanadas se estivesse no Ensino Presencial. Apenas dois alunos afirmaram que não aprenderam, justificando sua resposta com as seguintes afirmações: "de diferente eu não aprendi quase nada"; "Eu já conhecia alguns conteúdos"; "Desaprendi muita coisa”; "Eu não sabia responder as coisas que eu já tinha estudado"; "Eu acho que piorei"; "Piorei na leitura, nas palavras para eu ler e nas respostas". Cabe ressaltar que um desses dois alunos obteve baixa frequência nas atividades remotas e não interagiu conforme esperado nas atividades impressas. Contudo, chama atenção o fato desses estudantes considerarem que houve retrocesso, e isso merece ser destacado. Talvez essa questão possa se tornar pauta para uma pesquisa qualitativa sobre memórias e esquecimento da aprendizagem no contexto de distanciamento físico causado pela pandemia da Covid-19.

\subsection{A opinião dos pais, mães ou responsáveis}

Considerando a presença dos pais, mães ou responsáveis na reunião virtual, o professor achou conveniente ouvi-los para compor uma avaliação final, bem como para extrair os olhares desses sujeitos, considerando que, desta vez, no Ensino Remoto Emergencial, eles foram decisivos para o desenvolvimento das atividades e dos processos de aprendizagem dos alunos.

A pergunta feita aos familiares reúne as três questões feitas aos alunos. Desse modo, o interesse era saber o seguinte: como você avalia as aulas remotas realizadas? Você acha que nome do aluno ou aluna - conseguiu aprender? Fale sobre isso.

As respostas dos pais ou responsáveis pelas crianças foram bem específicas e diversas. Das dez crianças que estavam acompanhadas no momento da reunião, cinco famílias enfatizaram que houve melhora no aprendizado e outros cinco deixaram subentendido que não. Dos que afirmaram positivamente, foram obtidas as seguintes justificativas: "Melhorou na escrita e 
leitura"; "Acho que melhorou"; "Consegue fazer contas e ler também"; Aprendeu a ler do ano passado pra cá, mas usei reforço por causa do tempo"; "Só um mês acho que melhorou, mas eu não sabia ajudar ele"; "Acho que aprendeu, porque é inteligente, sempre se preocupava se o professor ligou"; "Ele está adiantado, e ela se empolgou. Se não fosse esses três meses - a aluna ficou sem realizar atividades - eu achei ela melhor do que no ano passado". Apesar de tímidas e contidas, essas respostas demonstram que os pais ou responsáveis reconhecem algum avanço na aprendizagem, embora as expectativas em relação ao que se espera de uma criança ao final de um ano letivo parecem não terem sido atingidas.

As afirmações negativas em relação à aprendizagem dos alunos foram ditas pela maioria dos pais ou responsáveis. Destacam-se as seguintes expressões: "Não foi bom"; "Presencial era bem melhor"; "Ele ia conviver com os colegas, tirar dúvidas"; "Mas, em relação à família teve mais aproximação com ele"; "Teve dificuldades, porque não pôde curtir o professor por causa da pandemia, mas acompanhou direitinho"; "Não foi muito bom por causa da pandemia. Pegava no pé, mas é melhor na escola junto do professor e colegas. Mesmo assim ele aprendeu, melhorou nas letras - caligrafia"; "As aulas on-line foram boas, mas na escola ele se desenvolvia muito. Em casa estava preguiçoso"; "As aulas na escola era melhor. Eu não sei ensinar"; "Eu acho que ele ficou do mesmo jeito, porque estudando em casa ele perdeu o interesse. Eu não estava em casa - trabalhando - e ele deixava - as atividades - de lado".

Esses recortes discursivos dos pais, mães e responsáveis demonstram, novamente, o papel da escola e dos professores como fundamentais para o processo de aprendizagem (FERREIRA, 2020). Mesmo colaborando, acompanhando e orientando os filhos, os responsáveis destacam a complexidade dessa responsabilidade, tendo em vista que as crianças necessitam de adultos por perto para que construam uma rotina de estudos e realizem as atividades propostas. Não obstante, essas famílias possuem condições diversas e adversas: trabalham e só estão disponíveis em horários noturnos; não sabem ou não compreendem os conteúdos e atividades; dividem o aparelho celular com outros filhos que também estudam, além de utilizá-lo como item pessoal etc. Diante disso, fica evidente que o tipo de acompanhamento feito durante o Ensino Remoto é reflexo das assimetrias sociais e subjetividades existentes nas famílias e isso reforça, inclusive, processos de exclusão (REBÊLO, 2005; SOARES, 2020).

Vale destacar que os dados gerados neste trabalho correspondem a uma realidade específica e, por isso, não podem e nem devem ser generalizados. Outrossim, este é um ponto de partida para que, no âmbito do ERE, seja priorizado o diálogo entre professores e escola, família e alunos. Conhecer essas realidades pode ajudar no planejamento, na organização - e reorganização - das atividades e no atendimento mais humanizado diante da situação de pandemia, afinal, o Ensino Remoto escancarou a porta "do lado de lá", ou seja, a vida social e familiar dos alunos, fato que, muitas vezes, é ignorado ou negligenciado pelas escolas, em face de um ensino centrado na instituição escolar, nos currículos das disciplinas e pouco na esfera social dos estudantes. 


\section{CONSIDERAÇÕES}

As discussões sobre a escola, enquanto espaço de socialização e de produção de múltiplas aprendizagens, tomaram um sentido diferente em virtude da pandemia da COVID-19. Se antes havia conviç̧ão da importância dessa instância social, com a pandemia ela se intensificou. Nesse sentido, é mister ressaltar que o fechamento temporário das escolas provocou mudanças drásticas nas relações familiares, pedagógicas, bem como na e para aprendizagem.

A socialização e a sociabilidade das crianças parecem ter sido os aspectos mais prejudicados. É através do contato presencial com professores e colegas que as crianças desenvolvem-se cognitiva, afetiva e socialmente. Não obstante, as mediações feitas pelas plataformas digitais cumprem papel decisivo para diminuir o impacto negativo da ausência do contato presencial na escola e com as pessoas. Nesse contexto, a família, primeira instância socializadora e educadora da criança, foi requisitada de modo mais intensivo na realização do Ensino Remoto Emergencial, considerando as impossibilidades e limitações das novas mediações docentes on-line ou não presenciais.

Cumpre ressaltar que cada uma das famílias imprime características e complexidades peculiares que precisam ser notadas e consideradas pela escola. $O$ fato de isso não ser levado em conta pode impactar, inclusive, na forma como os alunos e a sociedade, de modo geral, veem a escola. Nesse entendimento, os resultados deste trabalho apontam para a necessidade de um diálogo constante, franco e aberto, acolhedor e honesto, entre escola e família.

Não só enquanto durar a pandemia, mas depois que ela passar, é pertinente que essa relação seja ampliada, mantendo abertas as "portas" e "janelas" que professores e escola precisaram "reconhecer do lado de lá". Ter esse olhar voltado para as realidades sociais das famílias, sobretudo as mais vulneráveis, reforça o papel da escola numa sociedade ainda muito desigual e injusta. Essas e outras questões muito evidentes durante a pandemia precisam de um novo olhar. O que este texto ofecere são pistas para outros desdobramentos e perspectivas sobre o assunto.

\section{REFERÊNCIAS}

BARDIN. L. Análise de conteúdo. Lisboa: Edições 70, 1977.

CASTELLS, M. A sociedade em Rede: do conhecimento à política. In: CASTELLS, M.; CARDOSO, G. (Org.). A Sociedade em Rede: do conhecimento à ação política. Conferência. Belém: Imprensa Nacional, 2005. Disponível em: https://egov.ufsc.br/portal/conteudo/sociedade-em-rede-do-conhecimento-\%C3\%A0ac\%C3\%A7\%C3\%A3o-pol\%C3\%ADtica. Acesso em: 26 fev. 2021.

COMITÊ GESTOR DA INTERNET NO BRASIL (CETIC.BR). Pesquisa sobre o uso das tecnologias de informação e comunicação nos domicílios brasileiros : TIC domicílios 2018. [livro eletrônico] São Paulo: NIC.BR/CETIC.BR, 2019. Disponível em: https://www.cetic.br/publicacao/pesquisa-sobre-o-uso-dastecnologias-de-informacao-e-comunicacao-nos-domicilios-brasileiros-tic-domicilios-2018/. Acesso em: 29 jan. 2021.

DELORS, J. et al. Educação: um tesouro a descobrir. Relatório para a UNESCO da Comissão Internacional sobre Educação para o século XXI. São Paulo: Cortez, 1998. Disponível em: 
http://dhnet.org.br/dados/relatorios/a_pdf/r_unesco_educ_tesouro_descobrir.pdf. Acesso em: 26 fev. 2021.

ESCOLA, J.; GOMES, A.; LOPES, N. Ser no ciberespaço: a comunicação educativa na WEB 2.0. In: LIMA, V. A. O.; NASCIMENTO, R. N. A.; ESCOLA, J. J. J. (Org.). Conhecimento, sociabilidade e humanidade: prenúncios de um novo tempo. Campina Grande: EDUEPB, 2018.

FERREIRA, G. Conversa com António Nóvoa. Porto Alegre, 06 abr. 2020. Facebook: sindprofnh. Disponível em: https://www. facebook.com/sindprofnh/videos/631629681020563/. Acesso em: 13 jan. 2021.

GUEDES, A. F. Os desafios do conhecimento na era tecnológica. . In: LIMA, V. A. O.; NASCIMENTO, R. N. A.; ESCOLA, J. J. J. (Org.). Conhecimento, sociabilidade e humanidade: prenúncios de um novo tempo. Campina Grande: EDUEPB, 2018.

MERCADO, L. P. L. Formação continuada de professores e novas tecnologias. Maceió: EDUFAL, 1999.

MORAN, J. Educação híbrida: um conceito-chave para a educação. In: BACICH, L.; TANZI NETO, A.; TREVISANI, F. M. Ensino híbrido: personalização e tecnologia na educação. Porto Alegre: Penso, 2015.

MORIN, E. A cabeça bem-feita: repensar a reforma, reformar o pensamento. 21. ed. Rio de Janeiro: Berthand Brasil, 2014.

MORIN, E. Os setes saberes necessários à educação do futuro. São Paulo: Cortez, 2002.

NASCIMENTO, R. N. A.; LIMA, V. O. Dimensões entrelaçadas do afeto e do saber: a educação de um novo tempo. In: LIMA, V. A.; NASCIMENTO, R. N. A.; ESCOLA, J. J. J. (Org.). Conhecimento, sociabilidade e humanidade. Campina Grande: EDUEPB, 2018.

WORLD HEALTH ORGANIZATION (WHO). WHO Coronavirus (COVID-19) Dashboard. 2021. Disponível em: https://covid19.who.int/. Acesso em: 30 jan. 2021.

RAMOS, A. T.; RAMOS, E. S. Os desafios da família nos processos de socialização escolar. Pátio Revista Pedagógica, Porto Alegre, n. 52, ano XIII, p. 32-35., nov. 2009-jan. 2010.

REBÊLO, P. Inclusão digital: o que é e a quem se destina?. 2005. Disponível em: https://docplayer.com.br/8242708-Inclusao-digital-o-que-e-e-a-quem-se-destina.html. Acesso em: 10 jan. 2021.

SANTOS, G. S. Espaços de aprendizagem. In: BACICH, L.; TANZI NETO, A.; TREVISANI, F. M. Ensino híbrido: personalização e tecnologia na educação. Porto Alegre: Penso, 2015.

SAVIANI, D. Pedagogia histórico-crítica: primeiras aproximações. 11. ed. Campinas: Autores Associados, 2011.

SOARES, S. B. V. Coronavírus e a modernização conservadora da educação. In: SOARES, S. B. V. et al. Coronavírus, educação e luta de classes no Brasil. Brasil: Terra Sem Amos, 2020.

'Disponível em: https://covid19.who.int/. 